\title{
Abdominal Region
}

National Cancer Institute

\section{Source}

National Cancer Institute. Abdominal Region. NCI Thesaurus. Code C139186.

Any portion of the body that lies within the boundary, either internally or externally, of the abdomen: superior margin, the thorax; inferior marg in the pelvis; lateral marg ins, the ribs. 